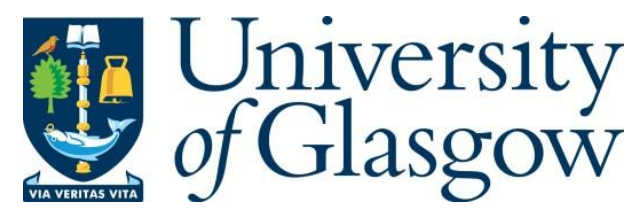

Yu, C.-E., Wen, J. and Yang, S. (2020) Viewpoint of suicide travel: An exploratory study on YouTube comments. Tourism Management Perspectives, 34, 100669.

There may be differences between this version and the published version. You are advised to consult the publisher's version if you wish to cite from it.

http://eprints.gla.ac.uk/213739/

Deposited on: 16 April 2020

Enlighten - Research publications by members of the University of Glasgow http://eprints.gla.ac.uk 
Management Perspectives

Elsevier Editorial System(tm) for Tourism

Manuscript Draft

Manuscript Number: TMP-D-19-00620R2

Title: Viewpoint of suicide travel: An exploratory study on YouTube comments

Article Type: Research Paper

Keywords: suicide travel; physician-assisted suicide; user-generated content; tourism

Corresponding Author: Dr. Jun Wen, Ph.D

Corresponding Author's Institution: Edith Cowan University

First Author: Chung-En Yu

Order of Authors: Chung-En Yu; Jun Wen, Ph.D; Shaohua Yang

Abstract: Tourism is often associated with recreation, leisure, or business; suicide travel-visiting a destination for the explicit purpose of ending one's life under a physician's guidance-starkly opposes traditional tourism definitions. Although physician-assisted suicide has been a focus of ethical debate, perceptions of suicide travel have not yet been addressed in the literature. This study presents a thematic content analysis of online comments to uncover people's reactions to physician-assisted suicide in a tourism context. Findings suggest that human rights, religion, legal issues, and fear of the dying process shape people's stances. Suicide travel can also include preliminary (i.e., informational) journeys. This study enhances knowledge about suicide travel, provides insight for tourism operators, and identifies relevant benefits.

Research Data Related to this Submission

There are no linked research data sets for this submission. The following reason is given:

Data will be made available on request 


\title{
Viewpoint of suicide travel: An exploratory study on YouTube comments
}

\author{
Chung-En $\mathrm{Yu}^{1}$ \\ Department of Innovation and Management in Tourism \\ Salzburg University of Applied Sciences \\ Urstein Süd 1, A-5412 Puch/Salzburg, Austria \\ Email: cyu.imte-m2018@fh-salzburg.ac.at
}

\author{
Jun Wen, $\mathrm{Ph} . \mathrm{D}^{1} *$ (Corresponding author) \\ School of Business and Law \\ Edith Cowan University \\ Joondalup, WA 6027, Australia \\ Email:j.wen@ecu.edu.au \\ Phone: +61863045413
}

Shaohua Yang

Graduate School of Business

Universiti Sains Malaysia

11800 Penang, Malaysia

Email: samuelyang0713@hotmail.com

Adam Smith Business School

University of Glasgow

G12 8QQ, United Kingdom

Email: 2463364Y@student.gla.ac.uk

${ }^{1}$ Note: Ms. Chung-En Yu and Dr. Jun Wen contributed equally to this manuscript and should be considered as co-first authors.

\section{Acknowledgement:}

The authors would like to express their gratitude to Professor Eva Brucker from Salzburg University of Applied Sciences for her valuable feedback and directions on this paper. Meanwhile, the authors wish to thank Professor Songshan (Sam) Huang from Edith Cowan University for his insightful comments to help improve the quality of this paper. 


\section{Highlights}

- This exploratory study analyses the public's perceptions of suicide travel based on YouTube video comments.

- Suicide travel starkly opposes traditional definitions of tourism.

- Suicide travel can include preliminary (i.e., informational) journeys.

- Human rights, religion, legal issues, and fear of the dying process inform perceptions of physician-assisted suicide. 


\section{Viewpoint of suicide travel: An exploratory study on YouTube comments}

\section{Abstract}

3 Tourism is often associated with recreation, leisure, or business; suicide travel—visiting a

4 destination for the explicit purpose of ending one's life under a physician's guidance — starkly

5 opposes traditional tourism definitions. Although physician-assisted suicide has been a focus of

6 ethical debate, perceptions of suicide travel have not yet been addressed in the literature. This

7 study presents a thematic content analysis of online comments to uncover people's reactions to

8 physician-assisted suicide in a tourism context. Findings suggest that human rights, religion, legal

9 issues, and fear of the dying process shape people's stances. Suicide travel can also include

10 preliminary (i.e., informational) journeys. This study enhances knowledge about suicide travel,

11 provides insight for tourism operators, and identifies relevant benefits.

12 Keywords: suicide travel; physician-assisted suicide; user-generated content; tourism

\section{1. INTRODUCTION}

14 Across cultures, humans have long searched for meaning while pursuing various goals. Unique

15 death rituals have existed since ancient times; in antiquity, such practices implied that

16 civilizations believed there was a deeper meaning to life apart from hunting and gathering

17 (Maisels, 2003). However, humans' ability to fully appreciate life is contingent on their physical

18 and psychological health; people can hardly seek greater meaning when ordinary needs are

19 unmet. This search for purpose also applies to tourists. Besides sightseeing and shopping (Lin,

20 Kerstetter, Nawijn, \& Mitas, 2014; Yüksel, 2007), individuals pursue meaning beyond

21 themselves and often explore their spirituality while travelling. Yet if aging, depression, or health

22 issues hinder a person's cognitive or physical development, survival motives may be

23 extinguished. David Goodall, an Australian scientist who fought to die on his terms, travelled to

24 Switzerland to end his life. Belinda Teh, a 27-year-old woman, embarked on a journey of 3

25 million steps to change an assisted dying law. Human beings are driven to pursue ultimate

26 happiness in everyday life and during travel. In the field of special interest tourism, tourists'

27 motivations and decisions are guided by individuals' interests in activities or destinations (Weiler

$28 \&$ Hall, 1992). Special interest tourism has birthed many interesting phenomena throughout the 29 early $21^{\text {st }}$ century (Rittichainuwat, 2018). Emerging topics such as wellness tourism (Sharma \& 30 Nayak, 2018), medical tourism (Mee, Cham, \& Chuan, 2018), dark tourism (Zhang, Yang, 
31 Zheng, \& Zhang, 2016), and suicide tourism (Gauthier, Mausbach, Reisch, \& Bartsch, 2015)

32 have grown in popularity as of late.

33 Similar to suicide tourism research by Gauthier et al. (2015) and Rittichainuwat (2018),

34 the current study replaces the term "tourism" with "travel." Suicide travel stands in stark contrast

35 to conventional recreational or business-related travel (UNWTO, 2012). A traveller's presumed

36 one-way ticket for physician-assisted suicide reinforces this distinction; the person's 'return' will

37 likely occur in a different form compared with conventional tourism (e.g., his/her body or

38 cremains). In this research, suicide travel is defined as potential suicide candidates' visits to

39 specific destinations to explore or commit to physician-assisted suicide, potentially because the

40 procedure is illegal in their own country (Dees, Vernooij-Dassen, Dekkers, Vissers, \& van Weel,

41 2011). It is also important to distinguish physician-assisted suicide from euthanasia; earlier

42 studies did not differentiate between these terms (Gauthier et al., 2015; Higginbotham, 2011)

43 when defining suicide tourism. Although physician-assisted suicide and euthanasia have been

44 used interchangeably among the general public, there are differences: physician-assisted suicide

45 involves lethal drugs or related paraphernalia administered under a patient's own volition

46 (Orentlicher, 1997); more generally, euthanasia refers to intentionally ending one's life to relieve

47 pain and suffering (i.e., by voluntary, non-voluntary, or involuntary means) (Seale \& Addington-

48 Hall, 1994). Essentially, physician-assisted suicide is performed with a doctor's assistance as long

49 as the family agrees to the practice, whereas euthanasia is physician-administered and can happen

50 without consent from the family. Yet a large knowledge gap remains around physician-assisted

51 suicide. Prior studies did not separate it from euthanasia (Emanuel, 2002; Emanuel, Daniels,

52 Fairclough, \& Clarridge, 1996), and it has rarely been investigated in tourism.

53 Countries where physician-assisted suicide is legal include Switzerland, the Netherlands, 54 and Belgium. Social values surrounding physician-assisted suicide have evolved over time. The 55 number of suicide travellers has climbed continuously since 2009 (Gauthier et al., 2015) amidst 56 rising awareness of physician-assisted suicide. Even so, little research has explored people's 57 perceptions of suicide travel. Although suicide travel may seem to have little to do with the 58 community, this practice potentially affects entire communities (e.g., via social conduct).

59 Strategically guiding people's understanding is crucial, especially regarding industry conflicts

60 (McLennan, Becken, \& Moyle, 2017). Because suicide travel can be closely related to 
61 governmental policies, it is particularly necessary to investigate community members' attitudes 62 and perceptions (Jamal \& Getz, 1995). Most studies related to suicidal behaviours have examined 63 patients' or medical providers' perceptions (Aghababaei \& Wasserman, 2013; Naseh, Rafiei, \& 64 Heidari, 2015; Wasserman, Clair, \& Ritchey, 2005); none appear to have focused on physician65 assisted suicide in the context of suicide travel.

$66 \quad$ Knowledge of suicide travel is in its infancy, and scarce research focused on death-related 67 tourism (Pratt, Tolkach, \& Kirillova, 2019). Suggested by Amatulli, Angelis, and Stoppani 68 (2019), one of the most effective ways to generate insight into an immature topic is by analysing 69 large and varied datasets to uncover hidden patterns or market trends behind explicit information, 70 particularly in exploratory studies. With the development of information communication 71 technology, people can share their opinions online, commonly known as user-generated content 72 (Amatulli et al., 2019). Popular user-generated content platforms include Facebook, Instagram, 73 and YouTube. Instead of employing traditional self-report assessments or face-to-face interviews 74 where the researcher's presence may confound results, analysing online reviews can be especially 75 helpful for learning about sensitive topics people might be unwilling to discuss due to the social 76 desirability bias. For instance, recent studies have explored the phenomenon of suicide travel 77 with a focus on self-determination (Yu, Wen, Goh, \& Aston, 2019) and travel constraints (Wen, $78 \mathrm{Yu}, \&$ Goh, 2019) through the analysis of online comments. As suggested by Guo, Barnes, and $79 \mathrm{Jia}$ (2017), it is more reliable to generate perceptions as the results are based on large samples 80 across different regions. In the same vein, to facilitate the development of a sound 81 conceptualisation of suicide travel for relevant industries and future research, perceptions from 82 people with differing backgrounds are fundamental. To bridge these areas, the present study aims 83 to reveal people's perceptions towards suicide travel based on user-generated content.

\section{2. LITERATURE REVIEW}

\section{2.1. Antecedents of suicidal behaviour}

86 Suicide travel has been studied in countries such as Germany, the UK, France, and Italy 87 (Gauthier et al., 2015). However, much research has merely highlighted the complexities of this 88 phenomenon in special interest tourism (Rittichainuwat, 2018). As tourism can take various 89 forms, it may not necessarily relate to pleasure travel (Yu, Wen, \& Meng, 2020) Nonetheless, no 90 strict definition of suicide travel yet exists in the literature because such travel can also be 
91 considered a niche segment of medical tourism (Higginbotham, 2011). In general tourism,

92 travellers often opt to participate in recreational activities to satisfy multiple needs (Ryan, 2003).

93 Inversely, a growing body of literature has examined tourists' motivations for requesting

94 physician-assisted suicide where the practice is legal (Dees et al., 2011; Norwood, 2007;

95 Pearlman et al., 2005). For instance, although individuals seeking physician-assisted suicide are

96 suffering from illness or aging, other factors affecting their quality of life can drive their wish for

97 death (Hendry et al., 2013). Baumeister (1990) found that most tourists pursuing physician-

98 assisted suicide shared a desire for freedom or escape. Iso-Ahola (1982) applied a tourism

99 framework for understanding leisure motivations and found that physician-assisted suicide could

100 provide an outlet for escaping something (i.e., the physical and psychological effects of a chronic 101 or terminal illness) while seeking something else (i.e., the fantasy or illusion of oblivion).

102 Gauthier et al. (2015) assumed a secondary approach and identified major antecedents of assisted 103 suicide in tourism destinations. Conditions such as neurological problems, rheumatic disease, 104 cancer, and chronic respiratory disease were common. Within a broader social science discipline, 105 van Orden et al. (2010) extended the interpersonal theory of suicide and identified several 106 antecedents of relevant decisions leading to suicide: family conflict, maternal disorders, previous 107 suicide attempts, physical illness, social isolation, and unemployment.

108 However, while van Orden et al. (2010) identified risk factors associated with future 109 suicidal ideation, little is known about suicide travel specifically. Travellers' attitudes before 110 deciding to engage in physician-assisted suicide in a tourism destination remain ambiguous. 111 Therefore, a comprehensive theory of suicidal behaviour should incorporate such components as 112 antecedents of suicidal ideation given that most individuals express negative attitudes before 113 committing suicide (van Orden et al., 2010). However, motivations specific to suicide travel may 114 be diverse. Echoing the avoidance theory of worry (Borkovec, Alcaine, \& Behar, 2004), suicide 115 travel can potentially be attributed to depression and anxiety. Outwardly, these travellers may 116 wish to avoid ongoing suffering from physical pain. Inwardly, they may seek escape from other 117 factors such as their growing social burden. Taken together, these emotions can unconsciously 118 contribute to travellers' intentions to select a destination in which to end their life. Perceived fear 119 and anxiety could increase the allure of death. 


\subsection{Perceptions of suicidal behaviour}

Several studies have developed measures to assess suicidal behaviour and investigate people's attitudes in this regard (Aghababaei \& Wasserman, 2013; Chong \& Fok, 2004; Naseh et al., 2015; Tang et al., 2010). The four dimensions developed by Chong and Fok (2004) offer one such example. Their identified domains of ethical considerations, practical considerations, treasuring life, and naturalistic beliefs have been widely applied in many studies related to suicide. Regarding ethical considerations, relevant discussions centre around human rights, humane acts, dignity, and terminal illness, among others. A study conducted with Muslim nurses indicated that $51.1 \%$ of nurses surveyed held negative attitudes and $46.3 \%$ held positive attitudes towards ethical considerations related to assisted suicide (Naseh et al., 2015). The dimension of practical considerations mainly addresses aging issues as well as patients' thoughts of being a social burden, especially to family members. Chong and Fok (2004) revealed that compared to physicians, public attitudes towards practical considerations are largely positive. Even so, many medical practitioners disagree with this dimension. The aspect of treasuring life refers to physicians' duties as well as debates around physical and psychological pain. Finally, the dimension of naturalistic beliefs captures the notion that people should not be kept alive artificially (e.g., by machines). Specifically, those who support suicidal behaviour tend to hold a naturalistic view of life. Poreddi, Nagarajaiah, Konduru, and Math (2014) identified other dimensions when evaluating people's attitudes towards suicidal behaviour: attitude towards the application, attitude towards the right to terminate life, family participation, and the influence of religion. One distinction between the dimensions identified by Chong and Fok (2004) and Poreddi et al. (2014) is religion. Poreddi et al. (2014) proposed that suicide candidates can be strongly influenced by their religion as well as a fear of death. Nevertheless, some items in the aforementioned dimensions overlap or are inconsistent, and the cited perceptions and attitudes towards suicidal behaviours were largely drawn from patients and medical practitioners (Chong \& Fok, 2004; Naseh et al., 2015; Poreddi et al., 2014).

Presumably, attitudes towards physician-assisted suicide represent an emerging issue that could affect the tourism industry. Travellers may be motivated to seek organisations' services to arrange suicide travel plans to destinations if the procedure is illegal at home (Miller \& Gonzalez, 2013). In areas where physician-assisted suicide is permitted (e.g., Switzerland, Belgium, the Netherlands, and Mexico), physician-assisted suicide has come under legal and ethical scrutiny 
(Miller \& Gonzalez, 2013). Research has also shown that physician-assisted suicide in tourism destinations can be considered criminal under the following conditions: suicide was attempted or completed at the behest of a third party; the third party acted on selfish grounds; and the third party acted deliberately (Guillod \& Schmidt, 2005). Views of physician-assisted suicide also vary around the globe. Countries have long debated whether doctors and other healthcare professionals should participate in a patient's intentional death and whether society should accept this practice as ethical (Vilela \& Caramelli, 2009). In addition, one study found that when evaluating suicidal behaviour, people tended to take animal euthanasia as an analogy (Ogden, Kinnison, \& May, 2012). Sanders (1995) suggested that animal euthanasia is less socially controversial than human euthanasia, as animals are thought to be mindless (Rollin, 1989). Furthermore, research has shown that religious beliefs greatly influence people's attitudes towards suicidal behaviour. For instance, the use of devices or medications intended to end human life is strictly prohibited in Islam (Zahedi, Larijani, \& Bazzaz, 2007). This tenet is grounded by the Muslim belief that death merely marks a transition between life on Earth and thereafter (Razban, Iranmanesh, \& Rafiei, 2013; Sarhill, LeGrand, Islambouli, Davis, \& Walsh, 2001).

166

167 168

\subsection{Practice of suicide travel}

Given that suicide travel is a relatively new phenomenon, it has been hotly debated from various social and psychological perspectives. Countries such as Switzerland, Belgium, the Netherlands, Mexico, and the U.S. have laws allowing certain forms of physician-assisted suicide under clearly defined circumstances. The debate gained renewed momentum when the Netherlands became the first country to legalise physician-assisted suicide in 2002, albeit under a strict set of conditions; for example, the procedure is limited to patients suffering from incurable diseases and unbearable pain (CNN, 2019). Under Swiss law, physician-assisted suicide can also be conducted for altruistic reasons (Humphry, 2002). These circumstances include an incurable illness, chronic mental state (e.g., depression), and specific requests of the person seeking assistance. While no consensus has been reached on physician-assisted suicide in various countries, suicide travel is expanding in line with travellers' needs. Scholars have found that physician-assisted suicide organisations are expanding (Miller \& Gonzalez, 2013). From a business perspective, physicianassisted suicide packages intend to provide potential clients options while stressing the rights and freedom they deserve as human beings. Jones (2012) noted that Dignitas, a Swiss non-profit organisation providing physician-assisted suicide, assisted 144 people in ending their lives in 
2011; this figure represented a 35\% increase over the previous year. Some organisations have even begun marketing suicide travel programmes by taking "the right to die" as their vision. Those companies believe that travellers who choose to end their own lives have the right to commit suicide whenever and wherever they please (Miller \& Gonzalez, 2013).

In the United Kingdom, Britons who travel to Switzerland to obtain lawful assistance to die have gained sustained public interest in the media. Physician-assisted suicide in Switzerland is arranged by privately run, non-profit organisations rather than healthcare providers (Ziegler \& Bosshard, 2007). Travellers applying to Dignitas must have evidence of terminal illness to meet criteria for the suicide travel programme (e.g., an unacceptably incapacitating disability or unbearable and uncontrollable pain with no hope of recovery) (Richards, 2017). Applications for suicide travel are inherently complicated due to the relative ambiguity of these criteria. Richards (2017) also noted that several documents are required before travellers can be considered candidates, some of which can be difficult to source. Applicants are warned that the approval process can take several months. Then, applicants may be issued a date for physician-assisted suicide (i.e., 'accompaniment'). All accepted applicants must undergo two rounds of consultation with a Swiss physician; the second round takes place 3 days after the first. These consultations are intended to ensure the applicant has not changed his/her mind. Irrespective of the industry, business is closely intertwined with marketing. In marketing communication, senders deliver information deemed relevant to the business via words, images, or presentation styles; at the same time, receivers digest the information they consider most salient to the business (Goffman, 1974). In the case of suicide travel, people choose to believe viewpoints congruent with their own. This notion further highlights the importance of understanding perceptions across a broader population (McLennan et al., 2017). Such considerations are especially essential for contemporary concepts (i.e., suicide travel); any socially disseminated information may influence future developments in suicide travel.

\section{METHODOLOGY}

208 This study applies a non-random sampling technique and unveils people's perceptions and 209 attitudes about suicide travel based on YouTube comments. As this topic is in its infancy, data 210 mining and text analysis techniques were applied (Amatulli et al., 2019) to gain an overview of 211 how suicide travel plays a role in the tourism industry. Following the procedure in Wen, Yu, and 
Goh's (2019) study, YouTube was selected as an information source given the vast video resources available on the platform. Additionally, Burgess and Green (2009) suggested that videos providing informational content attract substantial viewership; thus, findings could be 215 high in external validity when drawing from large samples across diverse regions (Guo et al., 216 2017). Litwin and Ngan (2019) further suggested that self-report questionnaires may be 217 insufficient to gain accurate responses about highly sensitive topics, as participants might be 218 reluctant to share their honest thoughts.

219 Similar to earlier studies (Yu et al., 2019; Wen et al., 2019), keywords such as "suicide travel," 220 "suicide tourism," and "suicide travellers" were entered into the search bar on YouTube. Results 221 were filtered based on view counts, and the researchers watched the videos in order of popularity. 222 Finally, the five most frequently viewed videos related to suicide travel were selected for analysis 223 (Table 1). Videos were chosen due to having highly similar content (e.g., an introduction to 224 physician-assisted suicide, suicide travellers, or suicide travel). Next, online comments were 225 scraped via Data Miner (https://data-miner.io), an online open-source software that can scrape 226 information from multiple websites automatically. Data mining was conducted in April 2019. To ensure that comments concerned video-based information rather than other commenters' thoughts, comment threads (i.e., dialogues) were excluded from analysis. For instance, among 1,484 comments on Video 1, 654 main comments were retained for analysis (Table 1).

\section{[Insert Table 1 here]}

Online comments were pre-processed upon completing data extraction. First, three nonEnglish comments were excluded. Comments were then split into several complete sentences based on end punctuation such as a period (.), question mark (?), or exclamation point (!) (Vu, Li, Law, \& Zhang, 2019). This differentiation strategy was adopted because online comments often address several aspects, and detailed insights tend to emerge at the sentence level. The final dataset consisted of 3,573 sentences generated from 1,231 main comments. Next, a hybrid approach to thematic content analysis was applied. The hybrid approach is well suited to examining underexplored topics given its inherent flexibility that allows for data- and theorydriven coding (Fereday \& Muir-Cochrane, 2006). Coding procedures began with a deductive approach, and additional themes were incorporated as the researchers familiarised themselves with the data. A pre-coding scheme was developed based on the dimensions used in the 
evaluation of attitudes towards suicidal behaviour (Naseh et al., 2015; Poreddi et al., 2014). Main

themes generated from the relevant literature included humane act, human rights, illness and disease, legal issues, and religious influences. Content analysis was conducted in NVivo 11. The researchers then proceeded to the first round of coding, during which themes such as usage intentions, tourists' motivations, and tourism-related issues were added.

Coding themes were finalised after the first round of coding. To avoid fatigue resulting from a continuous coding process, a 1-week break was taken between the second and third coding rounds. In addition to excluding online comments written in languages other than English, sentences that were unrelated to the pre-defined themes or otherwise outside the study's scope were omitted. Examples include comments sharing viewers' personal experiences (e.g., "I have lived with physical pain from nerve damage in my spine") or comments unrelated to video contents (e.g., "The background music is annoying"). Finally, interrater reliability was tested using Cohen's Kappa (McHugh, 2012); the value was 0.83, suggesting high coding consistency. Table 2 lists detailed information regarding the coding scheme.

\section{[Insert Table 2 here]}

\section{RESULTS}

\subsection{Attitudes towards suicide travel}

Focusing on attitudes towards suicidal behaviour, results revealed five issues as mentioned by viewers of the chosen YouTube videos: humane act, human rights, illness and disease, legal issues, and religious influences. The humane act category was related to debates around preventing the suffering of animals. Human rights refer to rights inherent to all individuals regardless of sex, age, nationality, or other qualifiers. In this study, human rights mainly concern whether human beings have the right to die. Sentences coded under illness and disease included references to potential suicide travellers' physical and mental states. Finally, influences of religion and general attitudes towards the legalisation of suicide travel were discussed.

\subsubsection{Humane act}

The top five words associated with humane act in videos' comment sections were "pets," "animals," "suffering," "humans," and "inhumane." Viewers frequently related and compared suicide travel to the practice of pet/animal euthanasia. In general, people disagreed upon the 
definition of humanity; they believed that if pet owners had the right to euthanise animals against their will, the same moral values should apply to human beings. Moreover, humanity and suffering were highly correlated. One viewer pointed out, "It is more humane to end something's suffering than it is to force them to live until their condition kills them."

\subsubsection{Human rights}

The topic of human rights attracted extensive viewer attention. Regarding basic human rights, several commenters agreed that human beings have the right to die and each person should make that decision. Viewers reasoned, "Individuals should be allowed to choose when to end their own life," "You should be allowed to die when you feel it's your time," and "Everyone should have a choice to die." Overall, "right," "life," "die," "choice," and "end" were the top five words viewers used. Dignity was frequently associated with death and represented a primary factor persuading viewers that suicide travel was acceptable. Commenters pointed out, "Everyone should have [the] right to dignified life and death," "It is our duty to help them keep their dignity," and "Let people die with dignity." However, when other factors such as illness and disease, legal issues, and religion were discussed alongside with human rights, commenters expressed different opinions. Relevant findings are presented below.

\subsubsection{Illness and disease}

Concerning whether patients have the right to die, $66 \%$ of commenters agreed, $7 \%$ disagreed, and $27 \%$ did not say. Those who supported suicide travellers believed that no one deserves to suffer from diseases that are incurable or terminal. One viewer stated, "If it's an illness that's never going to be cured and you're suffering..." In this regard, "terminal" and "suffering" were mentioned most frequently. Several viewers also believed that people should have the right to become suicide travellers in cases of mental illness (e.g., "I also think [physician-assisted suicide] should be available for anyone even the mentally ill"). Contrarily, those who disagreed with the practice of suicide travel contended that human beings should not abandon life easily. One commenter pointed out, "Why should we complain about suffering?"

\subsubsection{Religious influences}

Results also indicated that religious beliefs shaped YouTube commenters' perceptions of suicide travellers. Nearly three-quarters of viewers (72\%) identified religion as a primary factor in their support of suicide travellers, whereas $28 \%$ considered suicide travellers to have disobeyed God's 
will. Viewers who agreed with suicide travellers most often used terms such as "afterlife," "forgive," and "heaven." Commenters seemed to conclude that God would forgive those who committed physician-assisted suicide to end their suffering. One commenter mentioned, "[God] will forgive you of your sins [in this case]." In addition, viewers suggested that potential suicide candidates should believe in an afterlife to relieve stress and anxiety: "When you believe [...] there is an afterlife, it can be less scary to know you're going to die." By contrast, some people reasoned that human beings do not have the right to end their life due to religion: "God gave us the gift of life and he is the only one to take it away" and "I believe God is our creator and holds the keys to death." On the other hand, several viewers argued that religious beliefs were not pertinent to suicide travel: "No religious reasons can be used against the right of suicide," "The rules for your religion only apply to you," and "If you ignore religious implications, things make sense?"

\subsubsection{Legal issues}

Most viewers believed suicide travel should be legal everywhere; "legal," "assisted," and "everywhere" were the top words in comments. For instance, viewers noted, "This should [be] legal everywhere," and "Whether I live, or die should not be decided by the government, so it should be legal" Yet several viewers objected to suicide travel, arguing, "Assisted suicide is morally wrong and it's illegal" and "Citizens should not have the right to kill themselves."

\subsection{Motivations and usage intentions}

Several viewers expressed interest in being suicide travellers should they need this service in the future (e.g., "I [hope] I could have this choice when the time comes"). Commenters also shared their opinions about suicide travellers' internal and external motivations. Similar to the earlier discussion about illness and disease, several viewers indicated that pain and suffering were the main motivators for physician-assisted suicide, such as, "If a person was endlessly suffering and they feel that [physician-assisted suicide] is their only option." Another commenter remarked, "Some are suffering from many illness[es] and don't want to endure the pain no more." Quality of life and fear of the dying process were other major motives: "[Assisted suicide] is [a] much better way to end life instead of living in a wasted way" and "Tf I had no quality of life, I would have been a suicide tourist." Regarding the dying process, viewers pointed out that "The thought of dying a slow, painful, expensive, death terrifies me" and "Assisted suicide solutions are so much 
better, quicker, less complicated."

Apart from intrinsic motivations, viewers were also influenced by external factors. Our findings suggest that one's commitment to suicide could be heavily driven by social considerations. In particular, "family," "care," and "money" appeared frequently in the online comments. First, commenters believed that staying alive would only place a greater burden on one's family: "When you see how family members spend days and nights there [in the hospital] for months, [...] you will just want to end your life." In addition, many viewers were concerned about the social burden for caregivers and doctors: "This is hell on the care giver too" and "It's selfish to keep on living and wasting resources if you have nothing left to live for."

\subsection{Tourism-related issues}

Although physician-assisted suicide is often discussed in light of ethical and legal controversies, the act is now gaining wider attention. This phenomenon is distinct from traditional tourism, which is characterised by recreation and joyfulness (Leiper, 1979). Suicide travel is the act of travelling to a country where physician-assisted suicide is legal in order to die (Gauthier et al., 2015). The results generated from online comments provide several insights into this tourism industry. Several viewers identified direct benefits of suicide travel to the transportation sector including airlines, roads and railways, and transportation infrastructure: "This phenomenon makes people travel thousands of miles" and "Travelling across the sea." Other viewers associated physician-assisted suicide with medical tourism: "I intend to go to Switzerland for euthanasia treatment" and "Leaving life in peace is a choice you have in Switzerland with their advanced medical technology."

Sightseeing and education level played roles in suicide travel, albeit differently from traditional perspectives. With respect to sightseeing, viewers noted that suicide destinations should present images that convey beauty and peacefulness: "That's a peaceful place to die happier" and "Switzerland is just a nice and beautiful country to do it in." Regarding education, commenters believed that travellers and suicide candidates can be informed and educated about this option: "It's better to inform people openly about the implications beyond ending their own life," "With assisted suicide, we can have a person see a counselor in such situations, and discuss the issue, and work it out," and "The trip will be really interesting to learn about it in [detail]." 


\section{CONCLUSION AND DISCUSSION}

This study uncovered people's perceptions and attitudes towards suicide travel. To enhance knowledge about this form of tourism, thematic content analysis was conducted based on YouTube online comments. In addition, YouTube commenters can provide fruitful insights to relevant industries because the information delivered by businesses related to suicide travel should incorporate various stakeholders' perspectives (McLennan et al., 2017). To the best of the authors' knowledge, relevant literature has primarily focused on people's perceptions and attitudes of other forms of suicidal behaviour (e.g., euthanasia) (Aghababaei \& Wasserman, 2013; Naseh et al., 2015; Wasserman et al., 2005). However, it is necessary to highlight the differences between physician-assisted suicide and other suicidal behaviour. As mentioned earlier, physician-assisted suicide differs from euthanasia even though the latter has been widely investigated in medical science. Suicide travel, including physician-assisted suicide, thus remains underexplored. The issue has garnered attention from the public and academia only recently. Although suicide travel is legal in a few countries (Richards, 2017), the results of this study imply that even some citizens of those countries are unaware of such legality. This finding underscores the importance of gaining a better understanding of suicide travel in the tourism and hospitality industry.

Drawing from the literature examining people's perceptions of suicidal behaviour, several topics were generated from YouTube video comments relative to commenters' attitudes (i.e., humane act, human rights, illness and disease, legal issues, and religious influences). First, given the immaturity of this topic, physician-assisted suicide was often framed similarly to the practice of animal euthanasia. A previous study compared people's attitudes towards animal euthanasia and suicidal behaviour, concluding that the two are distinct (Ogden et al., 2012). However, findings from the present study provide a different view. YouTube viewers tended to agree that physician-assisted suicide was akin to euthanising an animal owing to increasing awareness of animal welfare from humans’ perspectives (Špinka, 2019). People’s perceptions might have also changed dramatically over the years. Another recent study examining pig euthanasia indicated that stockpersons' attitudes towards this action varied according to individuals' characteristics and knowledge (Rault, Holyoake, \& Coleman, 2017). Furthermore, a main reason why people shared similar stances on suicide travel involved human rights (Ghahremani, 2018). Similar to Miller and Gonzalez's (2013) study, YouTube viewers asserted that human beings have the right 
to die and to die with dignity. Therefore, the growing popularity of suicide travel has led to associated business expansion (Miller \& Gonzalez, 2013). The notion of dignity was also identified as a main motive behind people becoming suicide travellers. This finding can be reinforced by Nuryanti (1996), who suggested that one's desire for dignity represents an intrinsic motive in postmodern tourism.

Nevertheless, the findings of this research reveal that people's attitudes may differ regarding the role of religion in suicide travel. Specifically, a belief in God can either lead to acceptance of or objections to physician-assisted suicide. Research has suggested that certain religions do not afford individuals the right to decide when to die (Zahedi et al., 2007), while other religions view death as a transition (Razban et al., 2013; Sarhill et al., 2001). Similar to the notion of religious tourism, where religion is a major travel motive (Terzidou, 2010), this study identifies individuals' religious beliefs as a main factor behind suicide travel. However, when religion was not taken into consideration, most YouTube viewers agreed that people suffering from terminal diseases have the right to die. Echoing an earlier point, people's association of physician-assisted suicide with humane acts (e.g., animal euthanasia) potentially explains their perceptions in this regard. Similarly, studies have shown that terminal illnesses or cancer are major antecedents of suicide travel (Gauthier et al., 2015; Richards, 2017). Consistent with motivation research, the desire for freedom, escape from reality, and reduced stress are other popular travel motives (Caber \& Albayrak, 2016; Fu, Cai, \& Lehto, 2015). Findings from YouTube comments suggest that suicide travellers possess similar desires for freedom or escape from reality (Baumeister, 1990; Hendry et al., 2013). Additionally, these results suggest several perceived benefits of committing suicide, such as reducing social burdens, alleviating pain, and avoiding fear of the dying process. Although one's sense of fear represents an internal motivation/affective attitude (Borkovec et al., 2004), it may cause unconscious shifts in their decision to become a suicide traveller.

Regarding the tourism industry, this study presents several revelations. First, YouTube viewers foresaw direct benefits of suicide travel to airline and rail transport. Suicide travellers must travel to a particular country to fulfill their wish to die, as such services are not available in most places. Viewers also considered suicide travel a type of informational journey. Specifically, suicide candidates will likely travel to a country more than once before reaching a final decision 
(Richards, 2017); that is, suicide candidates learn about the process of physician-assisted suicide throughout their journey, as does their family. This notion reflects travellers' needs to acquire knowledge during a trip. A plethora of literature has framed travel as a means of satisfying educational needs (Mohammad \& Som, 2010; Yousefi \& Marzuki, 2012). In this case, suicide candidates might stay in the country for several days with family members. During their stay, candidates, who are acting as travellers, can visit clinics, meet people in similar circumstances, and gain a better understanding of the consequences of their potential decision. The main purpose of such a trip is to become informed. Hence, as revealed in the findings, suicide travel may be considered an informational journey. Presumably, travellers - regardless of their interest in committing physician-assisted suicide in a given destination - do visit the place to gain information and become educated. This informational journey is not limited to patients and their family members but is instead open to anyone who is interested in understanding the treatment and process of physician-assisted suicide.

\section{5.1. Practical implications}

435 This study provides valuable insights for various stakeholders that may be involved in the 436 emerging issue of suicide travel. First, the findings can offer relevant stakeholders a better 437 understanding of people's perceptions and attitudes towards tourists who wish to engage in 438 physician-assisted suicide through suicide travel to end their life. Individuals arguably possess the 439 right to choose to die with dignity, especially when suffering from terminal illness. Perceptions of 440 these people must be considered when developing laws around the use of suicide travel to end 441 one's life. Support should be solicited from professional organisations in destinations such as 442 Switzerland, the Netherlands, and Germany when enacting relevant legislation. Training 443 programmes should also be established to outline professional guidelines for tourism operators; 444 such training can help operators more effectively assist tourists interested in suicide travel. As a 445 complement to these programmes, relevant tourism legislation and monitoring systems must be 446 in place to ensure suicide travel is strictly open to those in genuine need. Last, considering 447 suicide travellers' health and psychological conditions, embassies in tourists' home countries and 448 overseas should allow for expedited visa applications and comprehensive support. Visa officers should carefully verify potential suicide travellers' application materials to prevent tourists from applying under this visa category for other travel purposes. 


\subsection{Limitations and recommendations}

Despite the comprehensive analysis in this study, the research is not without limitations. First, given the relative anonymity of online comments, this study broadly examined perceptions of suicide travel based on a group of people who had viewed and commented on the selected videos; individual differences were not considered. Notably, YouTube comments do not necessarily identify people's connections to related industries. Therefore, future research should incorporate demographic factors such as gender, cultural background, religious beliefs, and education. Meanwhile, as the sampling technique was non-random, results could be limited and may not be applicable to the general public. Second, because suicide travel is an emerging and sensitive topic, empirical research should consider various stakeholders to gather comprehensive data. While in-depth interviews and surveys are encouraged, future studies could also use mixed methods (e.g. implicit and explicit tests) to compare results owing to the social desirability bias.

463 Third, individuals' perceptions of suicide travel will likely change over time as the issue becomes 464 more well known. It would be interesting to conduct a longitudinal study to track the topic's 465 evolution; doing so could also provide solid evidence about this tourism market. Lastly, future 466 suicide travel research should incorporate legal perspectives to paint a clearer picture of this 467 phenomenon. Multidisciplinary research should be undertaken to inform legislation around this 468 tourism practice as well.

\section{REFERENCES}

Aghababaei, N., \& Wasserman, J. A. (2013). Attitude toward euthanasia scale: Psychometric properties and relations with religious orientation, personality, and life satisfaction. The American Journal of Hospice \& Palliative Care, 30(8), 781-785.

Amatulli, C., Angelis, M. de, \& Stoppani, A. (2019). Analyzing online reviews in hospitality: Data-driven opportunities for predicting the sharing of negative emotional content. Current Issues in Tourism, 22(5), 1-14.

Baumeister, R. F. (1990). Suicide as escape from self. Psychological Review, 97(1), 90-113.

Borkovec, T. D., Alcaine, O., \& Behar, E. (2004). Avoidance theory of worry and generalized anxiety disorder. Generalized Anxiety Disorder: Advances in Research and Practice, 77-108. 
Burgess, J., \& Green, J. (2009). YouTube: Digital media and society series. Polity.

Caber, M., \& Albayrak, T. (2016). Push or pull? Identifying rock climbing tourists' motivations. Tourism Management, 55, 74-84.

Chong, A. M. L., \& Fok, S. Y. (2004). Attitudes toward euthanasia in Hong Kong - A comparison between physicians and the general public. Death Studies, 29(1), 29-54.

CNN. (2019). Physician-assisted suicide fast facts. Retrieved from https://edition.cnn.com/2014/11/26/us/physician-assisted-suicide-fast-facts/index.html

Dees, M. K., Vernooij-Dassen, M. J., Dekkers, W. J., Vissers, K. C., \& van Weel, C. (2011). 'Unbearable suffering': A qualitative study on the perspectives of patients who request assistance in dying. Journal of Medical Ethics, 37(12), 727-734.

Emanuel, E. J. (2002). Euthanasia and physician-assisted suicide: A review of the empirical data from the United States. Archives of Internal Medicine, 162, 142-152.

492 Emanuel, E. J., Daniels, E. R., Fairclough, D. L., \& Clarridge, B. R. (1996). Euthanasia and 493 physician-assisted suicide: Attitudes and experiences of oncology patients, oncologists, and the public. The Lancet, 347(9018), 1805-1810.

Fereday, J., \& Muir-Cochrane, E. (2006). Demonstrating rigor using thematic analysis: A hybrid approach of inductive and deductive coding and theme development. International Journal of Qualitative Methods, 5(1), 80-92.

Fu, X., Cai, L., \& Lehto, X. (2015). A Confucian analysis of Chinese tourists' motivations. Journal of Travel \& Tourism Marketing, 32(3), 180-198.

Gauthier, S., Mausbach, J., Reisch, T., \& Bartsch, C. (2015). Suicide tourism: A pilot study on the Swiss phenomenon. Journal of Medical Ethics, 41(8), 611-617.

Ghahremani, D. (2018). Tourism development and human rights. Journal of Tourism Hospitality Research, 6(3), 39-48.

Goffman, E. (1974). Frame analysis: An essay on the organization of experience. Harvard University Press.

506 Guillod, O., \& Schmidt, A. (2005). Assisted suicide under Swiss law. European Journal of Health 17 
Law, 12(1), 25-38.

Guo, Y., Barnes, S. J., \& Jia, Q. (2017). Mining meaning from online ratings and reviews: Tourist satisfaction analysis using latent Dirichlet allocation. Tourism Management, 59, 467-483.

Hendry, M., Pasterfield, D., Lewis, R., Carter, B., Hodgson, D., \& Wilkinson, C. (2013). Why do we want the right to die? A systematic review of the international literature on the views of patients, carers and the public on assisted dying. Palliative Medicine, 27(1), 13-26.

Higginbotham, G. (2011). Assisted-suicide tourism: Is it tourism? Tourismos: An International Multidisciplinary Journal of Tourism, 6(2), 177-185.

Humphry, D. (2002). Law reform. Retrieved from https://www.assistedsuicide.org/suicide_laws.html

Iso-Ahola, S. E. (1982). Toward a social psychological theory of tourism motivation: A rejoinder. Annals of Tourism Research, 9(2), 256-262.

Jones, K. (2012). 2011: Dignitas assisted deaths rose by 35\%. Retrieved from https://www.medindia.net/news/2011-dignitas-assisted-deaths-rose-by-35-97757-1.htm

Leiper, N. (1979). The framework of tourism: Towards a definition of tourism, tourist, and the tourist industry. Annals of Tourism Research, 6(4), 390-407.

Lin, Y., Kerstetter, D., Nawijn, J., \& Mitas, O. (2014). Changes in emotions and their interactions with personality in a vacation context. Tourism Management, 40, 416-424.

Litwin, A., \& Ngan, H. (2019). Measuring implicit attitudes in socially sensitive topics:

Practicalities of implicit association test. SAGE Publications Limited.

Maisels, C. K. (2003). The emergence of civilization: From hunting and gathering to agriculture, cities, and the state of the Near East. Routledge.

McHugh, M. L. (2012). Interrater reliability: The kappa statistic. Biochemia Medica, 22(3), 276282.

McLennan, C.-1. J., Becken, S., \& Moyle, B. D. (2017). Framing in a contested space: Media reporting on tourism and mining in Australia. Current Issues in Tourism, 20(9), 960-980. 
Mee, Y. L., Cham, T. H., \& Chuan, S. B. (2018). Medical tourists' behavioral intention in relation to motivational factors and perceived image of the service providers. International Academic Journal of Organizational Behavior and Human Resource Management, 5(3), 1-16.

Miller, S. D., \& Gonzalez, C. (2013). When death is the destination: the business of death tourism - despite legal and social implications. International Journal of Culture, Tourism and Hospitality Research, 7(3), 293-306.

Mohammad, B.A.M.A.H., \& Som, A. P. M. (2010). An analysis of push and pull travel motivations of foreign tourists to Jordan. International Journal of Business and Management, $5(2), 41-50$.

Naseh, L., Rafiei, H., \& Heidari, M. (2015). Nurses' attitudes towards euthanasia: A crosssectional study in Iran. International Journal of Palliative Nursing, 21(1), 43-48.

Norwood, F. (2007). Nothing more to do: Euthanasia, general practice, and end-of-life discourse in the Netherlands. Medical Anthropology, 26(2), 139-174.

Nuryanti, W. (1996). Heritage and postmodern tourism. Annals of Tourism Research, 23(2), 249260.

Ogden, U., Kinnison, T., \& May, S. A. (2012). Attitudes to animal euthanasia do not correlate with acceptance of human euthanasia or suicide. The Veterinary Record, 171(7), 174-177.

Orentlicher, D. (1997). The Supreme Court and physician-assisted suicide-rejecting assisted suicide but embracing euthanasia. The New England of Journal of Medicine, 337, 1236-1239.

Pearlman, R. A., Hsu, C., Starks, H., Back, A. L., Gordon, J. R., Bharucha, A. J., Koeing, B. A., \& Battin, M. P. (2005). Motivations for physician-assisted suicide. Journal of General Internal Medicine, 20(3), 234-239.

Poreddi, V., Nagarajaiah, K. R., \& Math, S. B. (2014). Euthanasia: The perceptions of nurses in India. International Journal of Palliative Nursing, 19(4), 187-193.

Pratt, S., Tolkach, D., \& Kirillova, K. (2019). Tourism \& death. Annals of Tourism Research, 78, 102758.

559 Rault, J. L., Holyoake, T., \& Coleman, G. (2017). Stockperson attitudes toward pig euthanasia. 
Journal of Animal Science, 95(2), 949-957.

Razban, F., Iranmanesh, S., \& Rafiei, H. (2013). Nurses' attitudes toward palliative care in southeast Iran. International Journal of Palliative Nursing, 19(8), 403-410.

Richards, N. (2017). Assisted suicide as a remedy for suffering? The end-of-life preferences of British "suicide tourists". Medical Anthropology, 36(4), 348-362.

Rittichainuwat, B. N. (2018). Special interest tourism, 3rd edition. Cambridge Scholars Publishing.

Rollin, B. E. (1989). The unheeded cry: Animal consciousness, animal pain and science. Oxford University Press.

Ryan, C. (2003). Recreational tourism: Demand and impacts (Vol. 11). Channel View Publications.

Sanders, C. R. (1995). Killing with kindness: Veterinary euthanasia and the social construction of personhood. In Sociological Forum (pp. 195-214). Kluwer Academic Publishers-Plenum Publishers.

Sarhill, N., LeGrand, S., Islambouli, R., Davis, M. P., \& Walsh, D. (2001). The terminally ill Muslim: Death and dying from the Muslim perspective. American Journal of Hospice and Palliative Medicine, 18(1), 251-255.

Seale, C., \& Addington-Hall, J. (1994). Euthanasia: Why people want to die earlier. Social Science \& Medicine, 39(5), 647-654.

Sharma, P., \& Nayak, J. K. (2018). Testing the role of tourists' emotional experiences in predicting destination image, satisfaction, and behavioral intentions: A case of wellness tourism. Tourism Management Perspectives, 28, 41-52.

Špinka, M. (2019). Animal agency, animal awareness and animal welfare. Animal Welfare, 28(1), $11-20$.

Tang, W. K., Mak, K. K., Kam, P. M. H., Ho, J. W. K., Chan, D. C. Y., Suen, T. L., Lau, M. C. K., Cheng, A. K. C., Wan, Y. T., \& Hussain, A. (2010). Reliability and validity of the Euthanasia Attitude Scale (EAS) for Hong Kong medical doctors. American Journal of Hospice \& 
Palliative Care, 27(5), 320-324.

Terzidou, M. (2010). Religion as a motivation to travel: The case of Tinos. 5(2), Tourism and Hospitality Planning \& Development, 338-349.

UNWTO. (2012). Understanding tourism: Basic glossary. Retrieved from http://www2.unwto.org/

592 Van Orden, K. A., Witte, T. K., Cukrowicz, K. C., Braithwaite, S. R., Selby, E. A., \& Joiner, T. E. 593 (2010). The interpersonal theory of suicide. Psychological Review, 117(2), 575-600.

594 Vilela, L. P., \& Caramelli, P. (2009). Knowledge of the definition of euthanasia: Study with 595 doctors and caregivers of Alzheimer's disease patients. Revista da Associação Médica 596 Brasileira, 55(3), 263-267.

597 Vu, H. Q., Li, G., Law, R., \& Zhang, Y. (2019). Exploring tourist dining preferences based on 598 restaurant reviews. Journal of Travel Research, 58(1), 149-167.

599 Wasserman, J., Clair, J. M., \& Ritchey, F. J. (2005). A scale to assess attitudes toward euthanasia. $600 \quad$ Omega, 51(3), 229-237.

601 Weiler, B., \& Hall, C. M. (1992). Special interest tourism: In search of an alternative. In Special 602 Interest Tourism (pp. 199-204). Belhaven Press.

603 Wen, J., Yu, C. E., \& Goh, E. (2019). Physician-assisted suicide travel constraints: thematic 604 content analysis of online reviews. Tourism Recreation Research, 44(4), 553-557.

605 Yousefi, M., \& Marzuki, A. (2012). Travel motivations and the influential factors: The case of 606 Penang, Malaysia. Anatolia, 23(2), 169-176.

607 Yu, C. E., Wen, J., \& Meng, F. (2020). Defining physician-assisted suicide tourism and travel. $608 \quad$ Journal of Hospitality \& Tourism Research. doi:10.1177/1096348019899437

609 Yu, C. E., Wen, J., Goh, E., \& Aston, J. (2019). “Please help me die”: applying self-determination 610 theory to understand suicide travel. Anatolia, 30(3), 450-453.

611 Yüksel, A. (2007). Tourist shopping habitat: Effects on emotions, shopping value and behaviours. 612 Tourism Management, 28(1), 58-69. 
Zahedi, F., Larijani, B., \& Bazzaz, J. T. (2007). End of life ethical issues and Islamic views. Iran $614 \quad J$ Allergy Asthma Immunol, 6(Suppl 5), 5-15. 615 Zhang, H., Yang, Y., Zheng, C., \& Zhang, J. (2016). Too dark to revisit? The role of past 616 experiences and intrapersonal constraints. Tourism Management, 54, 452-464. 617 Ziegler, S. J., \& Bosshard, G. (2007). Role of non-governmental organisations in physician 618 assisted suicide. BMJ, 334(7588), 295-298. 
Table 1. Most frequently viewed videos related to suicide travel

\begin{tabular}{|c|c|c|c|c|c|c|}
\hline No. & Views & $\begin{array}{l}\text { Total } \\
\text { comments }\end{array}$ & Main comments & Date & Publisher & Video length \\
\hline Video 1 & 226,346 & 1,484 & 654 & 31-Aug-14 & Seeker & $4: 17$ \\
\hline Video 2 & 104,952 & 689 & 342 & 3-Мау-18 & The Betamax Man & $55: 37: 00$ \\
\hline Video 3 & 83,225 & 303 & 122 & 21-Oct-14 & NowThis World & $2: 52$ \\
\hline Video 4 & 71,077 & 102 & 68 & 8-Aug-12 & 16x9onglobal & $9: 43$ \\
\hline Video 5 & 9,641 & 158 & 45 & 25-Aug-14 & Secular Talk & 7:03 \\
\hline
\end{tabular}

Note: Video 1: https://www.youtube.com/watch?v=31kkhq4kxxs\&t=137s

Video 2: https://www.youtube.com/watch? $\mathrm{v}=$ BtQFdOEN3eA

Video 3: https://www.youtube.com/watch?v=hEHLW9xD8Zg

Video 4: https://www.youtube.com/watch?v=vaR4xx2si6g

Video 5: https://www.youtube.com/watch?v=RLDNIME5pYo

Table 2. Summary of coding scheme

\begin{tabular}{|c|c|c|}
\hline Themes & Frequency & Description \\
\hline \multicolumn{3}{|l|}{ Attitudes towards suicide travel } \\
\hline Humane act & 80 & Discussion of preventing suffering in animals \\
\hline Human rights & 550 & Discussion of right to die \\
\hline Illness and disease & 132 & $\begin{array}{l}\text { Discussion of physical and mental status of potential } \\
\text { suicide travellers }\end{array}$ \\
\hline Legal issues & 434 & $\begin{array}{l}\text { General public's attitudes towards legalisation of } \\
\text { suicide travel }\end{array}$ \\
\hline Religious influences & 258 & Discussion of roles of religious beliefs \\
\hline Motivation and usage intentions & 347 & $\begin{array}{l}\text { Discussion of motivations to commit PAS and } \\
\text { intentions to become suicide travellers }\end{array}$ \\
\hline Tourism-related issue & 75 & Discussion of issues related to tourism industry \\
\hline
\end{tabular}




\section{Author Biographies}

Chung-En Yu received a BSc in Tourism Event Management from Institute for Tourism Studies (IFT) Macau. Currently she is a master student in Innovation and Management in Tourism at Salzburg University of Applied Sciences. Her research interests center on the psychological and sociological phenomena, consumer experiences and emerging technologies in tourism and hospitality.

Dr. Jun Wen is a lecturer in tourism and hospitality management in the School of Business and Law at Edith Cowan University. His current research interests lie in Chinese outbound tourism marketing, behaviours, and other related aspects.

Shaohua Yang is a PhD candidate in the Graduate School of Business at Universiti Sains Malaysia. He is also currently a PhD exchange student (Erasmus funding) in Adam Smith Business School at University of Glasgow, United Kingdom. His PhD research topic is about Chinese revisit intention to New Zealand: a behavioural analysis of Chinese outbound tourists His current research interests lie in tourism marketing, tourist behaviour, special interest tourism, self-congruency and destination personality. 


\section{Author Photo}

Chung-En Yu
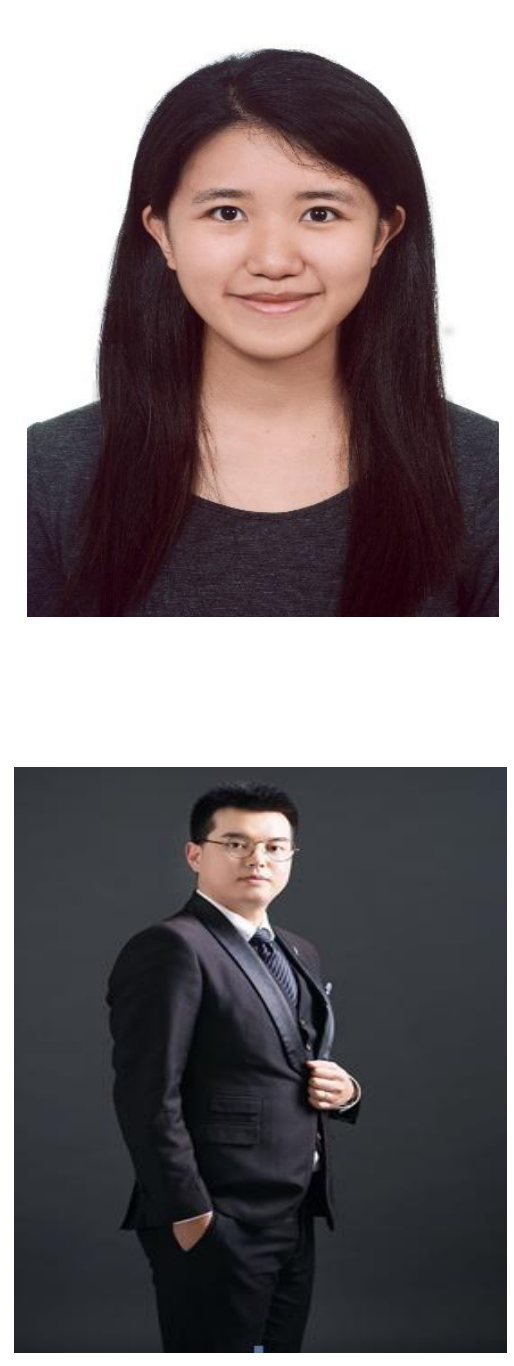

Dr. Jun Wen

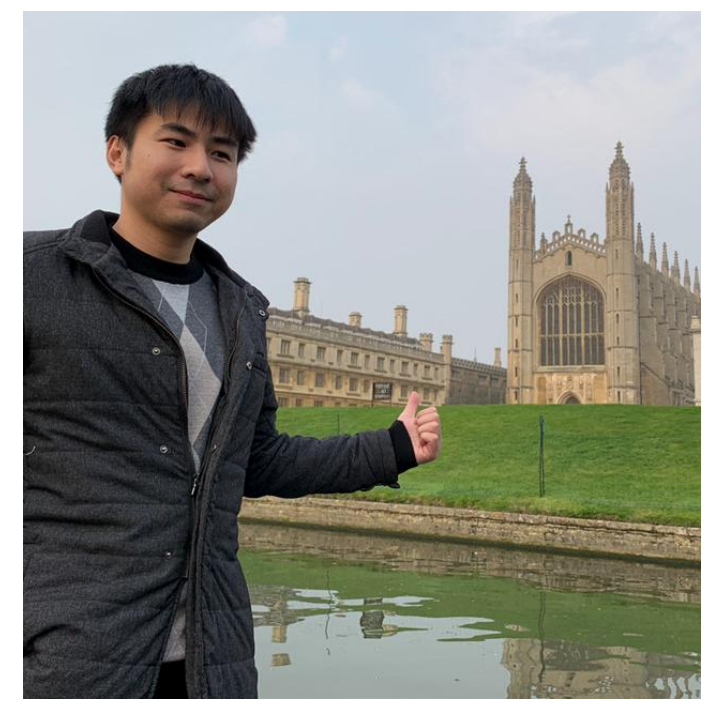

Shaohua Yang 